\title{
O ESPAÇO PÚBLICO NA CONTEMPORANEIDADE DA CIDADE: ESTUDO DE CASO BAIRRO SANTA LUZIA - CRICIÚMA (SC) ${ }^{1}$
}

\section{THE PUBLIC SPACE IN THE CONTEMPORARY CITY: A CASE STUDY THE DISTRICT OF SANTA LUZIA - CRICIÚMA (SC)}

\author{
Ramilho Fernandes Rodrigues ${ }^{2}$ \\ Nilzo Ivo Ladwig ${ }^{3}$

\section{Resumo}

Os espaços públicos assumem diferentes formas e tamanhos na cidade contemporânea, os quais são projetados para o uso cotidiano da cidade. Neste estudo são identificados como sendo espaços públicos as ruas, calçadas e praças do bairro Santa Luzia, município de Criciúma, Estado de Santa Catarina. Pesquisadores argumentam que os espaços públicos de convivência na cidade contemporânea estão encolhendo, e consequentemente, este processo está gerando um recuo da cidadania. A pesquisa é importância ao colocar em pauta o espaço público como um direito de cidadania. Portanto, por meio da análise da estrutura física, funcionalidade e entrevistas com moradores, originou-se um diagnóstico da funcionalidade dos espaços públicos presentes no bairro Santa Luzia. No estudo foi constatado que neste bairro: as ruas dão prioridade para os carros, suas calçadas estão mal conservadas e da mesma forma as praças existentes perderam sua característica fundamental, ou seja, a de promover o encontro e a convivência entre os moradores da urbe. Diante destes resultados, constatou-se a necessidade de valorização desses espaços públicos com o intuito de torná-los atrativos a seus usuários e promover o uso social, possibilitando assim, o encontro, o convívio social e a prática da cidadania.

Palavras-chave: Cidadania, Funcionalidade, Convívio social, Espaço Urbano.

\begin{abstract}
Public spaces take on different shapes and sizes in the contemporary city, which are designed for everyday city use. This study is identified as public spaces streets, sidewalks and plazas district of Santa Luzia, municipality of Criciúma, State of Santa Catarina. Researchers argue that the public living spaces in the contemporary city are shrinking, and consequently, this process is generating a backlash of citizenship. The research is important to put on the agenda the public space as a right of citizenship. Therefore, by analyzing the physical structure, functionality and interviews with residents, there diagnostic feature of public spaces present in the district of Santa Luzia. In the study it was found that in this neighborhood: the streets give priority to cars, their sidewalks are poorly maintained and similarly the existing plazas lost its fundamental characteristic, namely, to promote contact and interaction among residents of the metropolis. Given this reality, there was the need for recovery of public spaces in order

\footnotetext{
${ }^{1}$ Monografia apresentada ao curso de Geografia Bacharel/Licenciatura na Universidade do Extremo Sul Catarinense. Trabalho de Conclusão de Curso disponível em: http://repositorio.unesc.net/handle/1/2097

2 Geógrafo, UNESC (Universidade do Extremo Sul Catarinense), e-mail: ramilhofernandes@yahoo.com.br

${ }^{3}$ Professor do Curso de Engenharia de Agrimensura e Programa de Pós Graduação em Ciências Ambientais - UNESC (Universidade do Extremo Sul Catarinense), Professor da UNISUL (Universidade do Sul de Santa Catarina), e-mail: ladwig@unesc.net
} 
to make them attractive to its users and promote the social use, thus enabling the gathering, social interaction and practice of citizenship.

Keywords: Citizenship, Functionality, Social Gathering, Urban Space

\section{INTRODUÇÃO}

Os espaços públicos na cidade contemporânea assumem diferentes formas e tamanhos, as avenidas, calçadas e praças que compõem o tecido urbano são espaços públicos considerados abertos e acessíveis a todas as pessoas, tais espaços são projetados para o uso cotidiano a fim de organizarem a malha urbana e garantir a circulação de pessoas, além de promover, em certos casos, a permanência e o lazer da população.

De acordo com Gehl e Gemzoe (2002), a função dos espaços públicos está ligada ao conjunto de atividades e eventos que são realizados no espaço urbano. As atividades realizadas nos espaços públicos podem ser divididas em três categorias: necessárias, opcionais e sociais.

As atividades necessárias estão diretamente relacionadas ao ato de caminhar, onde a pessoa se desloca no espaço fazendo o trajeto de sua residência ao trabalho, às compras, à escola, enfim, são atividades rotineiras que acontecem em seu cotidiano na vida urbana.

As atividades opcionais nascem a partir do desejo de uma pessoa de frequentar determinado espaço público para fins como tomar sol, passear e contemplar a paisagem, ou seja, constituem-se numa opção particular de cada indivíduo. As atividades sociais, como jogos esportivos em grupos ou rodas de conversas, se referem às práticas sociais que podem ser desenvolvidas em um espaço público.

Muitos dos espaços públicos como calçadas, ruas e praças estão mal conservados, principalmente nos bairros dos grandes centros urbanos. Estes espaços, abandonados pelo poder público e principalmente pela população se tornam locais inseguros e consequentemente são evitados. Assim, na maioria dos casos, esses espaços atendem somente as atividades necessárias, pois as pessoas não tem escolha, pois precisam circular por estas áreas em suas atividades do dia a dia.

A falta de atratividade e confortabilidade dos espaços públicos têm afastado seus usuários, o que limita a realização das atividades opcionais e sociais por parte de seus usuários que acabam evitando permanecer por muito tempo nesses espaços em função 
da insegurança. Como consequência disso, cresce o número de espaços privados como shopping, clubes, parques fechados, condomínios, dentre outros.

Neste contexto, os espaços públicos como ruas, calçadas e praças estão perdendo sua característica fundamental, ou seja, a de terreno de convivência, de encontro entre diferentes, de convívio social, de espaço democrático. Portanto de acordo com Gomes (2002), verifica-se na cidade contemporânea um recuo da cidadania, o qual está vinculado à diminuição dos espaços públicos.

Este encolhimento dos espaços públicos associado à perda de sociabilidade entre seus usuários é um processo que está ocorrendo nas ruas e praças do bairro Santa Luzia, localizado na porção oeste da cidade de Criciúma (SC).

Diante desta realidade, o presente trabalho objetivou realizar um diagnóstico desses espaços para caracterizar as funções dos espaços públicos no bairro Santa Luzia por meio da análise de sua estrutura física e de sua funcionalidade. Partindo-se de um diagnóstico da funcionalidade desses espaços públicos, foram elaboradas sugestões que possam vir a contribuir na promoção e no uso social desses referidos espaços.

O objetivo geral desta pesquisa é realizar um diagnóstico da estrutura física e da funcionalidade das características dos espaços públicos no bairro Santa Luzia, em Criciúma - SC para instrumentalizar ações de planejamento e gestão destes locais.

Os objetivos específicos se resumem em três itens;

- Caracterizar a função dos espaços públicos na malha urbana do bairro Santa Luzia na contemporaneidade da cidade;

- Avaliar a compreensão dos moradores sobre os espaços públicos disponíveis no bairro no que diz respeito à segurança e qualidade dos locais;

- $\quad$ Propor sugestões que possam contribuir com a comunidade e o poder público municipal na promoção do uso social dos espaços públicos no bairro Santa Luzia em Criciúma, Santa Catarina.

Carlos (2003, p. 58) comenta que o surgimento das cidades está intrinsicamente ligado às necessidades humanas de viver em grupo, pois no momento em que o homem deixa de ser nômade, fixando-se no solo como agricultor, constituiu-se ai um primeiro passo para a formação das cidades, e depois, quando o homem começa a dominar técnicas agrícolas menos rudimentares, que permitem-lhe extrair um pequeno excedente, é dado o impulso para o surgimento das cidades. 
Ainda segundo Carlos (2003, p. 59), a origem das cidades se confunde com o princípio da hierarquização social, desta forma pode-se vincular a existência das cidades a seis elementos principais: a divisão do trabalho; a divisão da sociedade em classes; a acumulação tecnológica; a produção dos excedentes agrícolas decorrente da evolução tecnológica, um sistema de comunicação e a concentração espacial das atividades não agrícolas.

Assim, a "cidade tem uma história; ela é a obra de uma história, isto é, de pessoas e de grupos bem determinados que realizam essa obra nas condições históricas" (LEFEBVRE, 1991, p. 47).

“As cidades existem em todo o mundo e se apresentam em diferentes tamanhos, mais nenhuma é igual à outra” (SPÓSITO, 2004, p. 13). “A cidade enquanto realização humana é um fazer-se intenso, ininterrupto [...], enquanto produto histórico e social tem relações com a sociedade em seu conjunto" (CARLOS, 2003, p. 67).

Souza (2005, p. 20) salienta que cerca da metade da população do globo vivem em espaços urbanos e que o processo de urbanização se intensifica a cada dia que passa. As grandes cidades são vistas como espaços de concentração de oportunidades, como acesso a moradia, saúde, cultura, educação e que também é percebida como um local poluído, degradado e inseguro, onde as pessoas vivem estressadas e amedrontadas com a violência e a criminalidade.

A complexidade das cidades contemporânea se constitui na edificação das relações sociais produzidas ao longo do tempo na organização do espaço humano. "As épocas se distinguem pelas formas de fazer, isto é, pelas técnicas. Os sistemas técnicos envolvem formas de produzir energia, bens e serviços, formas de relacionar os homens entre eles" (SANTOS, 2006, p. 115). "E o capitalismo vai contribuir para a aceleração do processo que leva à internacionalização das técnicas, antes mesmo de desembocar, neste fim de século, em sua globalização" (SANTOS, 2006, p. 35).

O espaço serve às necessidades da acumulação através das mudanças e readaptações de usos e funções dos lugares e estes por sua vez, também são recriados sob a lei do reprodutível, a partir de estratégias do desenvolvimento do capitalismo que se estende cada vez mais ao espaço global, criando novos setores de atividade como extensão das atividades produtivas. (CARLOS, 2007, p. 26). 
Desta forma, "o acesso ao espaço na cidade está preso e submetido ao mercado no qual a propriedade privada do solo urbano aparece como condição do desenvolvimento do capitalismo." (CARLOS, 2007, p. 27).

O crescimento urbano com o foco no desenvolvimento econômico baseado no modelo capitalista, explorando os recursos, obtendo lucros e focado na propriedade privada sem privilegiar a perspectiva social, potencializa os conflitos entre as classes e a ocupação territorial desordenada, acentuando os problemas urbanos de foco social e estrutural (PREIS, 2013, p. 82).

De acordo com Santos (2001, p. 46) nos últimos cinco séculos de desenvolvimento e expansão geográfica do capitalismo, a concorrência se estabeleceu como regra e motivou a competição em todas as esferas sociais. A competitividade característica do nosso tempo tem a guerra como norma, pois esmaga o outro para tomar o seu lugar. Estes comportamentos que justificam todo desrespeito às pessoas são, afinal, uma das bases da sociabilidade atual e isto se revela nos individualismos presentes nas variadas esferas do conjunto.

Diante do exposto o quadro 1 que segue abaixo aborda os aspectos principais de cada tipo de individualismos.

Quadro 1: Individualismos presentes nas variadas esferas do conjunto

\begin{tabular}{|l|l|}
\hline \multicolumn{1}{|c|}{ Individualismos } & \multicolumn{1}{c|}{ Principais aspectos } \\
\hline Na vida econômica & $\begin{array}{l}\text { - A maneira como as empresas batalham umas com as outras para } \\
\text { garantir sua estabilidade financeira e gerar lucros. }\end{array}$ \\
\hline Na ordem da política & $\begin{array}{l}\text { - A maneira como os partidos frequentemente abandonam a ideia de } \\
\text { política para se tornarem simplesmente eleitoreiros. }\end{array}$ \\
\hline Na ordem do território & $\begin{array}{l}\text { - A maneira como as cidades brigam umas com as outra e as regiões } \\
\text { reclamam soluções particularistas. }\end{array}$ \\
\hline Na ordem social e individual & $\begin{array}{l}\text { - São individualismos arrebatadores e possessivos, que acabam por } \\
\text { constituir o outro como coisa. }\end{array}$ \\
\hline
\end{tabular}

Fonte: Santos, 2001, p. 47

De acordo com Carlos (2007, p. 14), verifica-se que atualmente está ocorrendo um novo conjunto de relações que revela a constituição de uma nova urbanidade, permeada pela mercadoria e pela recusa do outro. Esta nova urbanidade em constituição se cria ora a partir do triunfo do objeto sobre o sujeito, ora pela exacerbação do individualismo que se reproduz como condição e produto da reprodução das relações sociais.

Portanto de acordo com Baldissera (2011, p. 7), as formas de apropriação dos espaços públicos na cidade contemporânea, também estão ligadas ao comportamento de seus usuários, com relação à individualização do homem a aos hábitos explícitos de possessão de grupos ou individualidades que demarcam espaços e criam limites 
simbólicos, intimidando a utilização dos espaços públicos em diferentes graus de intensidade.

Segundo Souza e Rodrigues (2004, p. 128), existem a separação de duas classes sociais em cidades capitalistas, a que detêm a propriedade privada dos meios de produção e a trabalhadora que vende sua força de trabalho. Nestas sociedades capitalistas a desigualdade econômica é essencial, pois a minoria rica explora a maioria pobre e o Estado que é composto pela elite, tende a tomar decisões que beneficiam sua classe rica.

Corrêa $(2000$, p. 7) define que o espaço de uma grande cidade capitalista se fundamenta no conjunto de diferentes usos da terra sobrepostos entre si, tais usos definem o centro da cidade como local das atividades comerciais, de serviços e de gestão, as áreas residenciais conforme a classe social, as áreas industriais, entre outras, desta maneira o complexo uso da terra organiza o espaço urbano e apresenta a cidade fragmentada.

"No espaço urbano, por exemplo, fundem-se os interesses do capital, a ação do Estado e a luta dos moradores como forma de resistência contra a segregação no espaço residencial e pelo direito à cidade" (CARLOS, 2003, p. 26). "Fragmentada, articulada, reflexo, condicionante social, a cidade é também o lugar onde as diversas classes sociais vivem e se reproduzem" (CORRÊA, 2000, p. 9).

Souza (2005, p. 84) indaga que em países em desenvolvimento como é o caso do Brasil, as cidades apresentam um quadro diversificado, a segregação está entrelaçada com a hierarquização social e a distribuição desigual da riqueza socialmente gerada, desta forma, a segregação derivada de desigualdades retroalimenta desigualdades ao condicionar a perpetuação de preconceitos e a existência de intolerância e conflitos.

De acordo com Souza (2005, p. 82), existem dois grandes conjuntos de problemas que estão fortemente associados à fragmentação das grandes cidades, a pobreza e a segregação residencial.

Carlos (1994, p. 195) ressalta que no caso do Brasil o acirramento das contradições urbanas é fruto do rápido crescimento, no qual o Estado coloca-se a serviço da reprodução ampliada do capital, desta forma o espaço urbano se reproduz, reproduzindo a segregação social. Os problemas urbanos ampliam-se conforme aumentam as desigualdades sociais e "[...] é cada vez mais gritante a contradição entre a 
produção da riqueza e a geração da pobreza, expressa no uso do solo e nas pautas de reivindicação dos movimentos urbanos" (CARLOS, 1994, p. 181).

Souza (2005, p. 91) revela que a fragmentação do tecido sociopolítico-espacial vai além de meramente um aumento das disparidades sociais. Assiste-se no Brasil de maneira consolidada, a um processo no qual, do ponto de vista sociopolítico que a cidade vai se fragmentando com consequenciais socioculturais sócio-políticas e psicossociais muito negativas.

Atualmente, segundo Souza (2005, p. 50), todas as cidades estão interligadas de modo direto ou indireto trocando informações e bens de consumo, elas também estão articuladas entre si, seja economicamente, culturalmente e politicamente. Assim, por intermédio da rede urbana as cidades estão ligadas pelo fluxo de pessoas, bens e informação, a rede também dá suporte à gestão e manutenção do território e aos mecanismos de exploração econômica e exercício de poder existentes em nossa sociedade.

O espaço urbano como produto social, em constante processo de reprodução, nos obriga a pensar a ação humana enquanto obra continuada, ação reprodutora que se refere aos usos do espaço onde tempos se sucedem e se justapõe, montando um mosaico que lhe dá forma e impõe característica a cada momento. (CARLOS, 2007, p. 56).

Desta forma “[...] por ser reflexo social e porque a sociedade apresenta dinamismo, o espaço urbano é também mutável, dispondo de uma mutabilidade que é complexa, com ritmos e natureza diferenciados" (CORRÊA, 2000, p. 149).

Relacionando o que Carlos (2003, p. 30) indaga sobre a reprodução do espaço urbano atrelado as condições de reprodução do capital, com o que Souza (2005, p. 82) explana sobre a fragmentação das cidades fortemente associada aos grandes centros urbanos e também com o que Santos (2001, p. 46) revela sobre a expansão geográfica do capitalismo que retroalimentando individualismos em todas as esferas sociais. Chegamos ao ponto chave de relacionar e averiguar que todas essas condições influenciam fortemente nas características físicas e funcionais dos espaços públicos na contemporaneidade da cidade, e também na forma de sociabilidade das pessoas que frequentam estes espaços destinados ao uso coletivo.

Serpa (2007, p. 9) entende que o espaço público é o espaço da ação política na contemporaneidade da cidade e este também é analisado dentro da lógica de produção e reprodução do sistema capitalista, como mercadoria para o consumo de poucos. 
"No ambiente urbano, diferentes formas de espaço público, sugerem diversas utilizações e apresentam diferentes características espaciais" (VIEIRA, 2010, p. 14). Para Alex (2008, p. 19), os espaços públicos nas cidades assumem inúmeras formas e tamanhos, e estes abrangem lugares designados ou projetados para o uso cotidiano, cujas formas mais conhecida são as ruas, as praças e os parques, logo, a palavra "público" indica que os locais que concretizam esses espaços são abertos e acessíveis a todas as pessoas.

Gomes (2002, p. 162) especula que fisicamente os espaços públicos seriam antes de tudo, "o lugar, praça, rua, shopping, praia, qualquer tipo de espaço, onde não haja obstáculos à possibilidade de acesso e participação de qualquer tipo de pessoa".

Desta forma, sendo os espaços públicos ou semi-públicos o lugar das diferenças, é primordial respeitar as regras de convívio e debate, pois "essa acessibilidade é física, mas também diz respeito ao fato de que não deve estar condicionada à força de quaisquer outros critérios senão daqueles impostos pela lei que regula os comportamentos em áreas comuns" (GOMES, 2002, p. 162).

Gomes (2002, p.188) constata que o recuo da cidadania e da convivência social está paralelamente ligado ao encolhimento dos espaços públicos na cidade contemporânea. $\mathrm{O}$ autor citado identificou quatro principais processos em que esse recuo da cidadania pode ser caracterizado: a apropriação privada crescente nos espaços comuns; a progressão das identidades territoriais (áreas controladas por gangues, traficantes ou grupos que territorializam o espaço); o isolamento da vida social (internet, shopping, esvaziamento das ruas); e o crescimento das ilhas utópicas (os condomínios fechados).

Alex (2008, p. 279) enfatiza que para promover a vida pública nos espaços públicos, deve-se primeiramente garantir o acesso público para que aconteça o uso coletivo como forma de apropriação desses espaços. Portanto, segundo Alex (2008, p. 25), a condição primordial para o uso dos espaços públicos é a sua acessibilidade, pois entrar em um lugar é condição inicial para poder usá-lo, e desta forma o acesso é fundamental para a apropriação e o uso de um espaço público.

Alex (2008, p. 19), verifica que atualmente os espaços públicos são plurifuncionais com suas praças, ruas, cafés, pontos de encontro e constitui-se uma opção em uma vasta rede de possibilidades de lugares, tornando-se difícil prever com 
exatidão seu uso urbano, esses espaços públicos são adaptáveis e redesenham-se dentro da própria transformação da cidade.

Com efeito, segundo Gomes (2002, p. 172), os espaços públicos abrigam em sua configuração física as práticas e dinâmicas sociais que ali se desenvolvem, tornando-o um conjunto indissociável das formas com as práticas sociais, estabelecendo uma relação direta entre a condição de cidadania e o espaço público, ou seja, sua configuração física, seus usos e sua vivência efetiva.

Com relação ao uso dos espaços públicos, Gehl e Gemzoe (2002, p. 10) verifica que as cidades sempre foram um lugar de encontro e reunião das pessoas, um local de troca de informações sobre a sociedade e também lugar de eventos importantes como, coroações, procissões, festas e festivais. Os padrões de uso dos espaços públicos variaram no decorrer da história e apesar dessas diferenças sutis, os espaços públicos sempre se fundou como lugar de encontro, comércio e de circulação.

Segundo Silva (2009, p.227), pode-se observar nos espaços públicos a variabilidade de acontecimentos sejam eles interligados, rotineiros ou eventuais, e que é possível constatar nos espaços públicos o reflexo da realidade das transformações ocorridas na cidade.

As pessoas utilizam os espaços públicos por diversas motivações, como caminhar ao trabalho ou a lazer ou para atender as suas atividades rotineiras, encontrar outras pessoas, descansar ou contemplar a paisagem, trabalhar em atividades lícitas ou ilícitas, transitar de carro, enfim uma variabilidade de uso.

Silva (2009, p. 30) e Baldissera (2011, p. 39) citam os trabalhos de Gehl (1987 e 2006), para explicar que a função dos espaços públicos está ligada ao conjunto de atividades e eventos que são realizados nestes espaços urbanos. Assim, as atividades realizadas nos espaços públicos podem ser divididas em três categorias: as necessárias, as opcionais e as sociais, as quais estão resumidas no quadro 02 que segue abaixo.

Quadro 02 - As três categorias do tipo de atividades que são realizados nos espaços públicos

\begin{tabular}{|l|l|}
\hline \multicolumn{1}{|c|}{ Tipo de atividade no espaço público } & \multicolumn{1}{|c|}{ Características } \\
\hline & $\begin{array}{l}\text { Estão diretamente relacionadas ao ato de caminhar, onde a } \\
\text { pessoa se desloca no espaço fazendo o trajeto de sua }\end{array}$ \\
As atividades necessárias & $\begin{array}{l}\text { residência ao trabalho, às compras, à escola. São atividades } \\
\text { rotineiras que acontecem em seu cotidiano na vida urbana. } \\
\text { Este tipo de uso do espaço público acontece por obrigação, o }\end{array}$ \\
\hline
\end{tabular}




\begin{tabular}{|l|l|}
\hline & $\begin{array}{l}\text { participante não tem escolha ou opção e sua incidência é } \\
\text { pouco influenciada pela estrutura física do espaço ou pelas } \\
\text { condições externas do ambiente, sejam elas favoráveis ou } \\
\text { desaforáveis. Desta forma, estas atividades transformam o } \\
\text { espaço público em um simples meio de ligação, uma rota } \\
\text { entre os pontos a transitar. }\end{array}$ \\
\hline As atividades opcionais & $\begin{array}{l}\text { Constituem-se numa opção particular de cada indivíduo, } \\
\text { nasce a partir do desejo da pessoa de frequentar determinado } \\
\text { espaço público para fins como tomar sol, passear, olhar a } \\
\text { paisagem, ou seja, são espaços destinados ao lazer e ao ócio, } \\
\text { nesses, incluem a maioria das atividades recreativas ao ar } \\
\text { livre. Nestes espaços públicos, as condições externas do } \\
\text { ambiente e as características físicas do lugar são favoráveis e } \\
\text { atrativas, tornando-o convidativo e criando maiores motivos } \\
\text { para que as pessoas usufruam e passem mais tempo nestes } \\
\text { lugares. }\end{array}$ \\
\hline As atividades sociais & $\begin{array}{l}\text { Se referem às práticas sociais que podem ser desenvolvidas } \\
\text { em um espaço público, estas dependem exclusivamente da } \\
\text { presença e interação das pessoas nesses lugares. Estas } \\
\text { atividades podem também ser chamadas de resultantes ou } \\
\text { consequentes, pois envolvem atividades relacionadas com as } \\
\text { categorias necessárias e opcionais. Estão inclusos nesta } \\
\text { categoria atividades como saudações e conversas, atividades } \\
\text { em conjunto de vários tipos, ver e ouvir os outros utilizadores } \\
\text { do espaço urbano entre outras ações de sociabilidade. }\end{array}$ \\
\hline
\end{tabular}

Fonte: Baldissera (2011, p. 39) e Silva (2009, p. 30).

\section{METODOLOGIA}

Com o intuito de alcançar os objetivos propostos neste estudo foram realizados levantamento bibliográfico, análise de dados obtidos no decorrer da pesquisa, entrevistas semiestruturadas, análise cartográfica e observação de campo direta e participante. Nesta pesquisa combinaram-se métodos e técnicas que permitiram a aproximação do sujeito com o objeto de estudo.

Por meio do estudo de caso dos espaços públicos no bairro Santa Luzia em Criciúma foram examinadas as características funcionais dos espaços públicos no referido bairro utilizando análise de sua estrutura física, funcionalidade e a compreensão desses espaços pelos seus usuários.

Assim, diante do exposto, o quadro 3 que segue abaixo é um demonstrativo que relaciona os objetivos específicos propostos com os procedimentos metodológicos realizados para a conclusão deste trabalho.

Quadro 3: Relação entre objetivos específicos e procedimentos metodológicos 


\begin{tabular}{|l|l|}
\hline \multicolumn{1}{|c|}{ OBJETIVOS ESPECÍFICOS } & \multicolumn{2}{|c|}{ PROCEDIMENTOS METODOLÓGICOS } \\
\hline $\begin{array}{l}\text { - Caracterizar a função dos espaços públicos na } \\
\text { malha urbana do bairro Santa Luzia na } \\
\text { contemporaneidade da cidade; }\end{array}$ & $\begin{array}{l}\text { Levantamento bibliográfico. } \\
\text { Observação direta na área de estudo de forma } \\
\text { sistemática no período de 01/10/13 à 23/10/13 com } \\
\text { registro fotográfico. } \\
\text { Observação participante com incursões } \\
\text { esporádicas. }\end{array}$ \\
\hline $\begin{array}{l}\text { - Avaliar a compreensão dos moradores sobre os } \\
\text { espaços públicos disponíveis no bairro no que diz } \\
\text { respeito à segurança e qualidade dos locais; }\end{array}$ & $\begin{array}{l}\text { Realização de oito (08) entrevistas } \\
\text { semiestruturada com moradores residentes do bairro } \\
\text { Santa Luzia em Criciúma. }\end{array}$ \\
\hline $\begin{array}{l}\text { - Propor sugestões que possam contribuir com a } \\
\text { comunidade e o poder público municipal na } \\
\text { promoção do uso social dos espaços públicos no } \\
\text { bairro Santa Luzia em Criciúma, SC. }\end{array}$ & $\begin{array}{l}\text { Com base na análise qualitativa das informações } \\
\text { levantadas, buscou-se identificar quais as ações e } \\
\text { projetos que possam contribuir na promoção do uso } \\
\text { social dos espaços públicos. }\end{array}$ \\
\hline
\end{tabular}

Fonte: autor

\section{CARACTERIZAÇÃO DA ÁREA E DISCUSSÃO DE RESULTADOS}

\subsection{Localização da área de estudo}

O município de Criciúma (SC) está inserido na Mesorregião Sul Catarinense entre as latitudes $28^{\circ} 38^{\prime} 02,53^{\prime \prime} \mathrm{S}$ e $28^{\circ} 51^{\prime} 18,42^{\prime \prime} \mathrm{S}$ e as longitudes $49^{\circ} 14^{\prime} 37,27^{\prime \prime O}$ e $49^{\circ} 28^{\prime} 43,45^{\prime \prime}$. Este município ocupa uma área de $235,709 \mathrm{~km}^{2}$ abrigando uma população de 192308 habitantes com densidade demográfica de 816,15 hab/km² predominantemente urbana (IBGE, 2013). Seus limites territoriais são com os municípios de Içara na porção leste, Nova Veneza e Forquilhinha a Oeste, Siderópolis, Cocal do Sul e Morro da Fumaça ao norte e Maracajá e Araranguá ao sul.

A configuração territorial e as atividades econômicas de Criciúma se alteraram com a descoberta e a exploração do carvão a partir de 1920 e a mineração do carvão se tornou a principal atividade econômica na região da Grande Santa Luzia até 1970. Após a década de 70 com o declínio da atividade mineira o comercio impulsiona a economia da região conhecida como a Grande Santa Luzia, a qual atualmente exerce papel de centralidade das atividades econômicas (POLICARPI, 2013).

O bairro Santa Luzia da região administrativa 10 com uma população de 24642 habitantes (IPAT, 2007), está integrado com a malha urbana da cidade de Criciúma e se localiza na porção oeste da cidade, junto ao limite municipal de Forquilhinha na porção oeste. Este bairro está inserido na bacia hidrográfica do Rio Sangão e foi criado pela Lei Municipal no 851 de 02 de dezembro de 1971 (CRICIÚMA). O referido bairro exerce papel de centralidade e se destaca como ponto central das atividades de seus moradores e da população dos bairros circundantes como Vila Manaus, Vila Nova Esperança, Vila Vitória, Progresso, São Sebastião, São Defende e Universitário. Sua principal via é a 
Avenida Universitária que concentra variadas atividades comerciais e contém em seu entorno serviços públicos como creches, escolas e unidade de saúde.

\subsection{Função dos espaços públicos no bairro Santa Luzia}

O referencial teórico deste trabalho serviu de suporte para o cumprimento da análise das características funcionais dos espaços públicos do bairro Santa Luzia. Portanto, foi realizado um diagnóstico das condições físicas das ruas, calçadas e praças desta região através de observação direta e participante. Também foi realizada uma análise da funcionalidade desses espaços públicos por meio da observação do fluxo diário de seus usuários e de quais tipos de usos são realizados nesses espaços urbanos.

\footnotetext{
$\mathrm{O}$ uso fornece elementos de articulação entre espaços públicos, promovendo e ampliando a diversidade dos usuários. Verificar o uso do espaço é fundamental para revelar as necessidades dos frequentadores e assinalar os pontos positivos e negativos dos lugares (ALEX, 2008, p. 27).
}

Os espaços públicos citados neste estudo referem-se ao conjunto de ruas, calçadas e praças presentes no tecido urbano do bairro Santa Luzia. Estes espaços apresentam variados tamanhos com diferentes formas e atualmente estão integrados com a malha urbana da cidade de Criciúma.

Diante disto foram realizadas observações sistematizadas, incursões esporádicas nos espaços públicos e oito entrevistas gravadas em áudio com alguns moradores. Estes dados serviram de subsídios para a análise de como a população utiliza os locais públicos e quais são as suas características funcionais dentro da malha urbana da cidade contemporânea de Criciúma.

Deste modo, para verificar a utilização e a função dos espaços públicos como ruas, calçadas e praças do bairro Santa Luzia foi estabelecido um trajeto, o qual pode ser visualizado e acompanhado na rota descrita na figura 1. Este procedimento permitiu que o pesquisador observasse de forma sistemática o comportamento dos usuários dos espaços públicos, em suas atividades rotineiras realizadas nos espaços urbanos do referido bairro.

Objetivando o contato e a interação com esses espaços públicos, o trajeto de 1350 metros foi percorrido a pé, entre os dias 01/10/2013 e 23/10/2013, em três horários alternados, período da manhã, tarde e noite. O trajeto percorrido nas observações sistemáticas deu subsídios para o autor na execução da análise dos espaços públicos no bairro Santa Luzia, este revelou de forma resumida a análise das condições físicas 
desses espaços relacionando-os com os pontos principais que atraem e influenciam o fluxo de pessoas nestes locais.

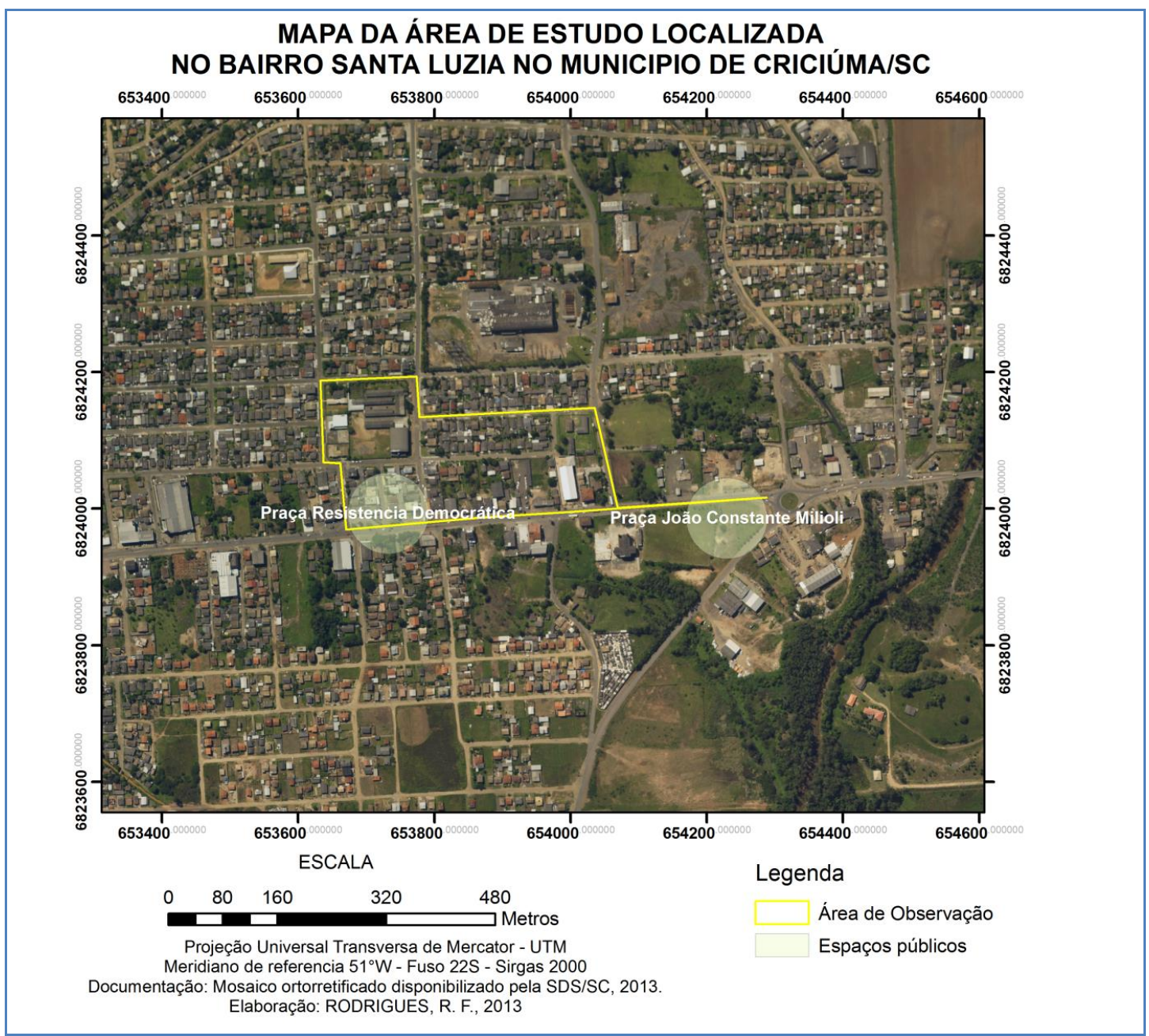

Figura 1: Mapa da área de estudo contendo o roteiro da observação participante

Ao analisar as ruas do bairro Santa Luzia, observou-se inicialmente que a Avenida Universitária é a principal via de ligação com o bairro Pinheirinho em uma extremidade e o bairro São Defende em outra. Esta via também é rota de passagem para o centro da cidade de Criciúma e para os municípios de Forquilhinha e Nova Veneza. Concentra-se nesta via, principalmente nos arredores da Praça da Resistência Democrática, variados estabelecimentos comerciais que atraem um grande fluxo de pessoas tanto do bairro Santa Luzia como de bairros vizinhos.

Analisando as calçadas existentes no bairro Santa Luzia foi observado que em grande parte do bairro não existem calçadas construídas e adequadas para passeio 
(deslocamento). O pedestre encontra muitos obstáculos nas calcadas, como acumulo de lixo, muitos desníveis, calçadas estreitas, carros estacionados sobre as mesmas gerando conflitos que levam o pedestre em muitos pontos a transitar pela rua, colocando em risco a sua integridade física.

Nas incursões sistemáticas e esporádicas pelo bairro, o que também chamou a atenção do autor, retratado na figura 2, foi o acúmulo de resíduos sólidos depositados nas calçadas e nos terrenos baldios. Este descaso com o espaço de uso comum revela o desrespeito da população com esses espaços públicos, a ineficiência das empresas de coleta de lixo e limpeza pública das vias e cabe aqui ressaltar que este lixo não destinado corretamente cria obstáculos nas calçadas prejudicando o fluxo dos pedestres e a imagem do bairro.
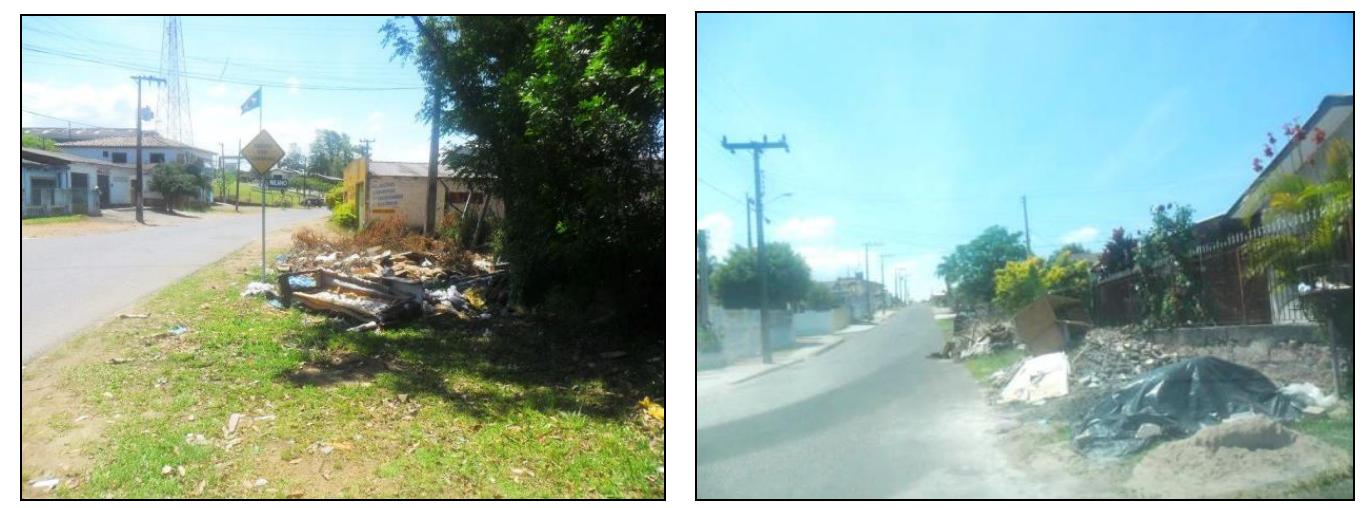

Figura 2 - Entulhos depositados em vias públicas e terrenos baldios

Fonte: do autor

Diante do exposto, em relação às condições das calçadas do bairro Santa Luzia concordar com Gonçalves (2009, p. 216) é pertinente quando afirma que:

\begin{abstract}
Os problemas encontrados nas calçadas da cidade de Criciúma nos remetem a uma situação de abandono e desrespeito pelo espaço público. Não oferecem segurança aos pedestres, muito menos a portadores de necessidades especiais, além de serem encontrados, ao longo, do percurso, buracos, desníveis, placas, vegetações inadequadas, sem ligações com os espaços das ruas. As pessoas não andam por elas, mas, sim, pelo meio das ruas. Por outro lado, os moradores se apropriam indevidamente das calçadas, utilizando-as como espaço privado e extensão dos próprios jardins, calando o sentimento de urbanidade inerente a essa concepção das calçadas como espaços públicos.
\end{abstract}

Existem no bairro Santa Luzia duas praças públicas destinadas ao uso coletivo da população. A Praça da Resistência Democrática situada na Av. Universitária, no 955 , denominada logradouro público urbanizado pela Lei Municipal n 3.147 de 29 de setembro de 1995 (CRICIÚMA) e a Praça João Constante Milioli situada na Av. 
Universitária, $\mathrm{n}^{\circ}$ 1072, denominada logradouro público urbanizado pela Lei Municipal n 3.962 de 21 de março de 2000 (CRICIÚMA).

A Praça da Resistência Democrática é um espaço reduzido, seus bancos não são projetados corretamente, pois não possuem encostos, as lixeiras feitas de cimento estão quebradas e a locadora de vídeo instalada neste endereço se apropria de parte do espaço da praça, para colocar pôsteres de filmes no jardim não conservado desta praça.

Verificou-se também que o monumento em memória aos desparecidos políticos durante o regime militar está estregue ao abandono e muitos moradores do bairro desconhecem a biografia dessas nobres pessoas que fizeram parte da história desse país.

Nas observações realizadas em campo constatou-se que a Praça João Constante Milioli, é uma localidade pouco frequentada pelos moradores do bairro e que ali não existem estabelecimentos comercias e atrativos para fazer a população usar este espaço. Averiguou-se que neste espaço lixo espalhado, seus bancos estão quebrados, a grama está alta e mal cuidada, e a junção desses fatores transmite uma imagem de lugar abandonado e inseguro.

Foi constatado durante a realização do estudo que em horários comerciais o fluxo de pessoas é maior em relação aos horários noturnos e fins de semana. As pessoas circulam pelas ruas, calçadas e praças para ir ao mercado, a padaria, a academia de ginastica, a escola, ao trabalho, enfim para executar suas atividades diárias e rotineiras. Nestes horários comerciais verificou-se que a lotérica e o posto de saúde são os locais de maior concentração de indivíduos.

De segunda-feira a sexta-feira após as 19hs, averiguou-se que o público da Praça Resistencia Democrática são usuários que se concentram no bar instalado nesta praça. A grande maioria deste público é composta por homens acima de 25 anos, que compram bebidas neste bar e sentam nos bancos da praça. Alguns adolescentes andam de skate, outros formam rodas de conversa e geralmente a polícia realiza abordagens e revistas nos usuários deste espaço público.

Nos fins de semana e feriado o movimento de transeuntes nos espaços públicos reduz consideravelmente em relação aos demais dias da semana. O bar da Praça Resistência Democrática continua atraindo o mesmo público e a Praça João Constante Milioli recebe alguns usuários que vão ali para assistir ou participar do jogo de futebol que ocorre em um campo que não é público, localizado na extremidade da referida 
praça. A partir das 20h00min, cosntatou-se que o movimento de pessoas é maior nas lanchonetes e pizzarias do bairro, a concentração de adolescentes do sexo masculino aumenta na Praça Resistencia Democrática e a Praça João Constante Milioli se torna um lugar inseguro em função do consumo de drogas ilícitas que ocorre neste local.

As atividades realizadas nos espaços públicos segundo Gehl e Gemzoe (2002), podem ser divididas em três categorias, as necessárias, as opcionais e as sociais. Portanto, embasado na proposta de Gehl e Gemzoe, objetivou-se verificar qual o conjunto de atividades e eventos realizados nos espaços públicos do bairro Santa Luzia para conseguir demonstrar quais são as funções desses espaços urbanos na contemporaneidade da cidade.

Diante do exposto, percebeu-se que ocorre um predomínio das atividades rotineiras que acontecem no cotidiano da vida urbana. $\mathrm{O}$ ato de caminhar, em que a pessoa se desloca no espaço fazendo o trajeto de sua residência ao trabalho, às compras, à escola é um tipo de uso do espaço público que acontece por obrigação, a pessoa não tem escolha ou opção e sua incidência é pouco influenciada pela estrutura física do espaço ou pelas condições externas do ambiente, sejam elas favoráveis ou desaforáveis.

Portanto, verificou-se que a função dos espaços públicos do bairro Santa Luzia atendem essencialmente as atividades necessárias do cotidiano, transformando a rede de espaços públicos como ruas, calçadas e praças em um simples meio de ligação, uma rota entre os pontos que devem ser transitados por obrigação ou necessidade.

\subsection{Segurança e qualidade dos espaços públicos no bairro}

A imagem de um espaço público é a expressão da vida comunitária do local, quando abandonados e degradados transmitem uma sensação de insegurança em suas ruas, calçadas e praças. Ao contrário, quando bem planejados e cuidados pelo poder público e principalmente pela população, estes espaços se tornam atrativos e convidativos para o uso social, promovendo o convívio e a interação de seus usuários, pois o espaço público é primeiramente...

O "espaço cidadão", o espaço monumental capaz de organizar um território, dar suporte diversos usos e funções, criar lugares, além de ser expressão coletiva da vida comunitária, da visibilidade, dos encontros cotidianos, o espaço da afirmação ou da confrontação, o espaço das grandes manifestações cidadãs ou sociais. (ABRAHÃO, 2008, p. 183). 
Para avaliar a compreensão dos moradores sobre os espaços públicos disponíveis no bairro Santa Luzia no que diz respeito à segurança e qualidade dos locais, foram realizadas entrevistas semiestruturada gravadas em áudio com oito residentes do bairro Santa Luzia compondo um grupo heterogêneo.

No que diz respeito às condições dos espaços públicos disponíveis no bairro Santa Luzia, os entrevistados reclamaram que as ruas e calçadas estão em péssimas condições. Uma moradora por iniciativa própria tenta chamar a atenção do poder público municipal quanto ao problema, colocando placa nos buracos da via conforme registro representado na figura 3.
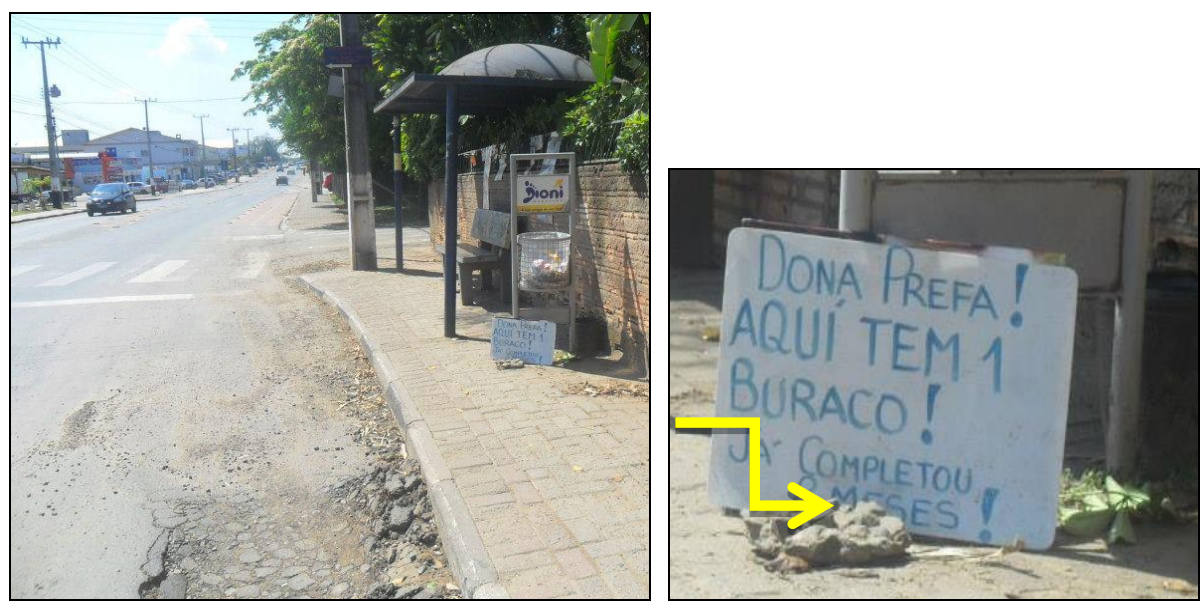

Figura 3: Ação de uma moradora para que a prefeitura tome providência na melhoria das condições da rede viária no detalhe a reinvindicação Fonte: do autor

Na pergunta norteadora sobre a utilização dos espaços públicos no bairro Santa Luzia, $87,5 \%$ dos entrevistados relataram que transitam pelos espaços públicos do bairro para ir a lotérica, ao mercado, a escola, ao trabalho, enfim, encontram no comercio da região e nos estabelecimentos institucionais os produtos e serviços que necessitam para o abastecimento de seu lar e a execução de suas atividades rotineiras, permanecendo no espaço público o tempo necessário para execução dessas atividades.

No que diz respeito ao local das práticas de atividades de lazer, 62,5\% responderam que gostam de frequentar o parque das nações, a praia e o shopping, enquanto que $25 \%$ preferem ficar em casa com a família e $12,5 \%$ disseram que não tem tempo para o lazer devido ao seu trabalho que exige dedicação e compromisso com a comunidade. Nesta questão verificou-se que os moradores não identificaram pontos de lazer no bairro, o que sugere que as praças não estão sendo usadas para esse fim. 
As entrevistas revelaram que os moradores compreendem que muitos dos espaços públicos do bairro são lugares inseguros, especialmente no período noturno, assim reivindicam mais policiamento, instalação de câmeras de segurança e medidas por parte do poder público que iniba os assaltos e roubos que ocorrem nesta região.

A análise das entrevistas e das observações em campo revelou que as atividades necessárias descritas por Gehl e Gemzoe (2002) predominam nos espaços públicos do bairro Santa Luzia. As atividades opcionais e sociais ocorrem com menos frequência por que os espaços públicos não são atrativos para o lazer e não proporcionam o uso social como forma de encontro e convívio comunitário.

Desta forma, se o espaço público não possibilita ações de sociabilidade, isto acaba prejudicando a relação de vizinhança, aumentando o confinamento nas residências e os problemas do bairro não são resolvidos devido à inercia e o individualismo de cada morador isolado em seu nicho familiar.

Assim, pode-se constatar que os entrevistados não identificam os espaços públicos do bairro como lugar de convívio e lazer, fazendo-os se deslocarem para outras localidades como o Parque das Nações, Praça do Congresso e a praia na busca de um lugar que proporcione o lazer e o encontro com os amigos.

\subsection{Promoção do uso social dos espaços públicos}

Santos (2001, p. 46) revela que a competitividade característica de nosso tempo amplia o individualismo em todas as esferas do conjunto, o que acaba inibindo e prejudicando as relações sociais nos espaços públicos na medida em que as pessoas deixam de usá-los como local de convívio e encontro com os personagens do lugar.

Gomes (2002, p. 174) verifica que a cidade na contemporaneidade é fragmentada, resultado da soma de parcelas mais ou menos independentes, existindo uma multiplicação de espaços que são comuns, mas não públicos, verifica-se então que há um confinamento dos terrenos de sociabilidade, pois existem diversas formas de nos extrairmos do espaço público (telefones celulares, fones de ouvido, etc.), e os modelos de lugares se redefinem, como shopping centers, ruas fechadas, "paredes cegas", etc.

Diante disto, Gomes (2002, p. 174) indica que de uma forma geral no mundo contemporâneo, está ocorrendo um processo de redefinição nos quadros da vida social coletiva, identificado pelo autor como "recuo da cidadania", o qual vem modificando os tipos de práticas sociais que ocorrem nos espaços públicos cada vez mais reduzidos. 
Constatou-se no bairro Santa Luzia, assim com na cidade de Criciúma que os espaços públicos principalmente as praças são reduzidas e não possibilitam a sociabilidade.

Os espaços públicos da cidade de Criciúma são muito restritos. Das 64 praças existentes, apenas duas cumprem a função social de uso, ou seja, as pessoas efetivamente desfrutam das mesmas. Estamos nos referindo à Praça Nereu Ramos e à do Congresso, que ficam no centro da cidade. As praças de bairro são pequenas nesgas de terreno, onde são colocados alguns mobiliários urbanos, como bancos, e não são apropriadas pela população do entorno (GONÇALVES, 2009, p. 215).

Os espaços públicos no Bairro Santa Luzia estão em péssimas condições, com calçadas desniveladas contendo em seu percurso muitos buracos e obstáculos e as praças do bairro não promovem o uso social, o que prejudica a possibilidade do encontro e da convivência social com os diferentes indivíduos da comunidade. Assim, desaparecendo o terreno da vida em comum, desaparecem também as formas de sociabilidade que unem os diferentes seguimentos sociais.

Revitalizar as calçadas e as praças do bairro com vistas a promover ao pedestre uma melhor condição para o seu deslocamento, construindo calçadas adequadas e ciclovias que liguem os bairro e centro da cidade podem possibilitar que as pessoas deixem o carro em casa e utilizem esses espaços para transpor as distâncias curtas.

Porém, antes de iniciar qualquer projeto de revitalização das praças e calçadas do bairro é essencial escutar os anseios da comunidade. Pois, a partir do trabalho conjunto entre poder municipal e população podem surgir ideias que possibilitem a criação de projetos adequados para a realidade do bairro, e que pode vir a contribuir na promoção do uso social dos espaços públicos do bairro Santa Luzia.

Recomenda-se que o poder público municipal e as comunidades de bairros trabalhem juntos, priorizando os interesses em comum para toda a cidade. Porque segundo Jacobs (2000, p. 130) “um dos maiores trunfos de uma cidade, é formar comunidades com interesses comuns. Por outro lado, um dos trunfos necessários aos distritos urbanos é contar com pessoas que tenham acesso a grupos políticos, administrativos e de interesse comum na cidade como um todo".

Para possibilitar a promoção do uso social dos espaços públicos do bairro Santa Luzia, torna-se essencial que o poder público tenha uma equipe multidisciplinar que planeje e atue em prol do cidadão e com o cidadão. 
Existem vários projetos, principalmente para as praças das grandes cidades, que objetivam promover o uso social dos espaços públicos para possibilitar o encontro e o convívio com os diferentes indivíduos usuários dos espaços urbanos.

Entretanto, para que esses projetos se concretizem e promovam o uso social dos espaços públicos, torna-se fundamental que a população se conscientize da importância desses espaços urbanos para o fortalecimento de sua comunidade.

Alex (2008, p. 126) ressalta que, “o convívio social no espaço público está intimamente relacionado às oportunidades de acesso e uso". Este arquiteto analisou seis praças da cidade de São Paulo e verificou que é necessário integrar as praças públicas ao tecido urbano, facilitando o acesso a esses espaços e oferecendo lugares com múltiplas funções para possibilitar o uso social e transformá-los em espaço público de convivência.

Jacobs (2000) ressalta a importância da utilização das calçadas na cidade, diz que a presença de pessoas nas ruas atraem outras pessoas. Assim, a diversidade de uso em todos os horários, a concentração de usuários e o balé de pessoas na boa calçada urbana transformam as ruas em lugares movimentados, proporcionando a vitalidade nos espaços públicos.

Promover as manifestações culturais e apresentações artísticas nos espaços públicos também possibilita o contato entre pessoas de todas as idades e promovem o uso social dos espaços públicos da cidade. Levar aos espaços públicos ao ar livre as apresentações artísticas, shows musicais, teatro dança, circo e oficinas de arte têm como objetivo principal proporcionar o uso social dos espaços públicos, pois se acredita que a utilização dos espaços públicos é uma das formas mais sagradas de exercício da cidadania, é assim que a cidade e cidadão se conectam, dando sentido um ao outro.

As feiras de bairro e apresentações teatrais podem estimular o uso social dos espaços públicos, porém resta saber se população tem interesse de participar dessas ações sociais, para tanto, cabe ressaltar que estas atividades devem ser planejadas em conjunto com o poder municipal e as associações comunitárias para garantir uma programação que atenda aos interesses da comunidade.

O projeto viva o bairro da prefeitura de Santos (SP) tenta aproximar a população com o poder municipal. Nas reuniões com a comunidade são levantadas sugestões e opiniões sobre os projetos e ações feitos pela administração municipal. Este programa, 
ilustrado na figura 4 que segue abaixo é dividido em três etapas para poder concretizar os objetivos propostos nas reuniões.

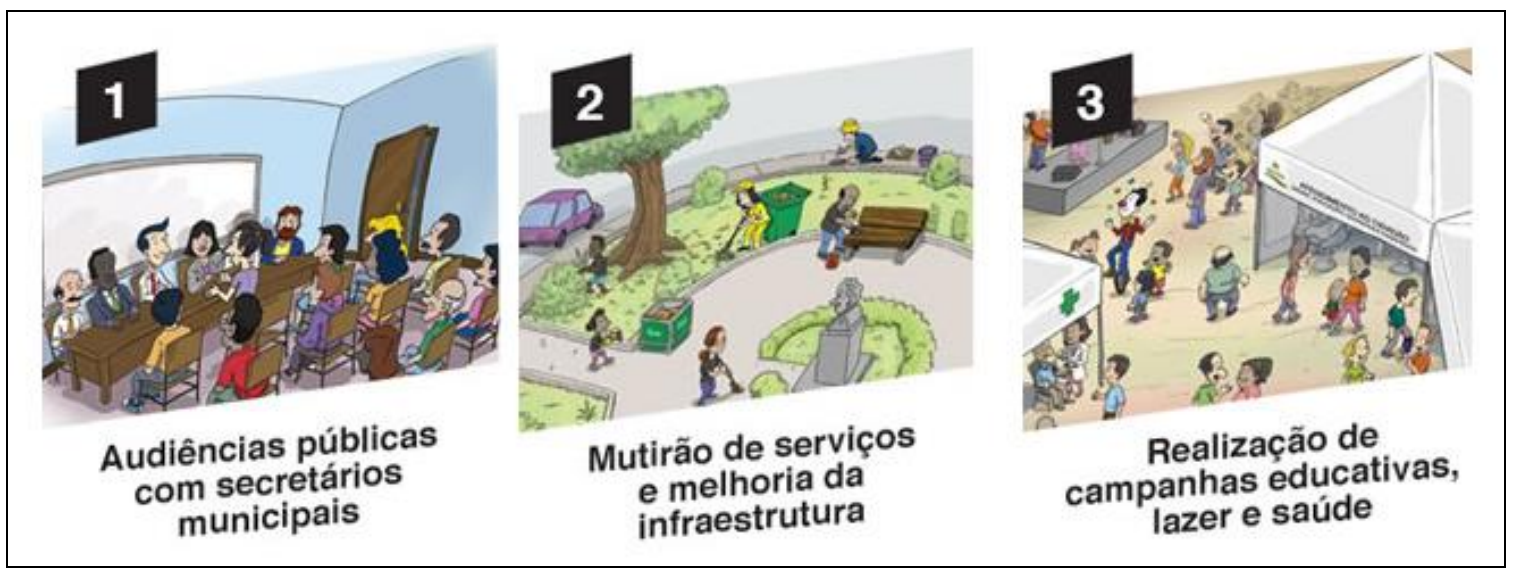

Figura 4: Fases do projeto viva o bairro da Prefeitura de Santos - SP

Fonte: Prefeitura de Santos (SP)

Chegamos até o momento há algumas sugestões e propostas que visam contribuir para a promoção do uso social dos espaços públicos na cidade, porém cabe ressaltar, que cada lugar é formado por pessoas com diferentes anseios e perspectivas e cada bairro tem suas peculiaridades expressa na imagem de seus espaços públicos.

Portanto, para estruturar sugestões que possam contribuir com a comunidade e o poder público municipal na promoção do uso social dos espaços públicos do bairro Santa Luzia é essencial envolver a comunidade na discussão de propostas adequadas para a revitalização e uso desses espaços públicos, pois é por meio das reuniões entre poder público e população que surgirão as ideias e propostas adequadas para a realidade do bairro na atualidade, e que efetivamente, venham proporcionar aos cidadãos do bairro um terreno de convivência, de encontro entre diferentes, de convívio social e de espaço democrático.

Preis (2013, p. 83) reflete que a cidade justa e igualitária pode ser uma utopia, mas a luta para melhorar a qualidade de vida e diminuir a desigualdade de acesso a equipamentos e serviços públicos, permeia a discussão das políticas públicas voltadas ao planejamento urbano e a efetiva participação da sociedade.

\section{CONCLUSÕES}

Verificou-se que é dever de todos, tanto do poder público municipal como dos cidadãos da urbe, que é essencial avaliar constantemente a qualidade dos espaços 
públicos dos bairros nas cidades contemporâneas, buscando identificar se esses espaços atendem as necessidades da população.

Conclui-se que a cidade está em constante transformação, e a geografia que se preocupa com os fenômenos urbanos vem enriquecer os debates, de forma crítica com vistas a atender os anseios sociais da grande maioria.

Pode-se concluir usando as argumentações dos autores citados neste estudo que os espaços públicos na contemporaneidade da cidade estão se reduzindo de tamanho. $\mathrm{O}$ individualismo gerado pelo capitalismo e o medo de frequentar os espaços abertos e públicos em função do crescimento da violência, leva as pessoas a se confinarem na segurança de seus lares. Desta forma, a vida social não é mais vivida como antes, e os espaços públicos acabam perdendo a sua função primordial, que seria a de promover o uso social com vistas a possibilitar o encontro e o convívio.

A partir das constatações verificadas neste estudo, conclui-se que a grande maioria dos espaços públicos da cidade, principalmente nos bairros carentes das urbes, estão decadentes e entregues ao abandono, tanto pelo poder público como pela população que depreda os mobiliários desses espaços, quebrando os bancos, aparelhos de ginasticas, jogando lixo nas vias públicas, enfim, toda a forma de manifestação que acaba em vandalismo, demonstra o desrespeito da população pelo bem público.

Portanto, com base na revisão de literatura, nas observações sistemáticas e esporádicas e nas entrevistas com os moradores, pode-se afirmar que os espaços públicos do bairro Santa Luzia servem essencialmente como uma mera rota para transitar na rede urbana. Suas ruas, calçadas e praças não atendem ao uso social e não possibilitam o convívio e o encontro com os moradores da urbe, pois as pessoas transitam apressadamente por esses espaços em suas atividades rotineiras da vida urbana e evitam permanecer muito tempo nos espaços públicos do bairro em função da falta de atratividade e confortabilidade desses espaços.

Assim, no caso específico do bairro Santa Luzia em Criciúma, os espaços públicos como ruas, calçadas e praças necessitam ser revitalizados e apropriados pela população para o fortalecimento do bairro. Diante do exposto, torna-se fundamental que os espaços públicos do bairro sejam tratados adequadamente pelos órgãos públicos responsáveis, e que principalmente, sejam evidenciados, vividos e apropriados pela população da cidade. 
Diante da complexidade do tema envolvido nesta pesquisa e da necessidade de promoção social dos espaços públicos para o exercício da cidadania e fortalecimento dos bairros na hierarquia da cidade, torna-se essencial a continuação de trabalhos investigativos sobre os espaços públicos da cidade com vistas a reverter este processo de recuo da cidadania citado por Gomes (2002) e promover o convívio social entre os moradores da cidade contemporânea.

\section{REFERENCIAS}

ABRAHÃO, Sérgio Luís. Espaço público: do urbano ao político. São Paulo: Annablume; FAPESP, 2008. 196p.

ALEX, Sun. Projeto da Praça: Convívio e exclusão nos espaços públicos. São Paulo: Editora Senac São Paulo, 2008. 291p.

BALDISSERA, Doris. Apropriação de espaços públicos em centros urbanos: Caxias do Sul 1910 - 2010. 2011. 240f. Dissertação (Mestrado em Planejamento Urbano e Regional) Universidade Federal do Rio Grande do Sul, Porto Alegre. Disponível em: $<$ http://www.ufrgs.br/propur/teses_dissertacoes/Doris_Baldissera.pdf $>$. Acesso em: 30 junho 2013.

CARLOS, Ana Fani Alessandri. A (Re)Produção do espaço urbano. São Paulo: Editora da USP, 1994. 270p.

. A cidade. 7. ed. São Paulo: Contexto, 2003. 98p.

O Espaço Urbano: Novos Escritos sobre a Cidade. São Paulo: FFLCH- Departamento de Geografia da USP, 2007. 123p. Disponível em: <http://gesp.fflch.usp.br/sites/gesp.fflch.usp.br/files/Espaco_urbano.pdf>. Acesso em 01 agosto de 2013

CORRÊA, Roberto Lobato. O espaço urbano. São Paulo: Ática, 2000. 94p.

Trajetórias geográficas. 2. ed. Rio de Janeiro: Bertrand Brasil, 2001. 302p.

CRICIÚMA (Santa Catarina). Lei Municipal no 851 de 02 de dezembro de 1971. Disponível em: <http://camara.virtualiza.net/conteudo_detalhe.php?id=755\&tipo=l\&criterio>. Acesso em 25 outubro de 2013.

. (Santa Catarina). Lei Municipal no 3.147 de 29 de setembro de 1995. Disponível em: $<$ http://camara.virtualiza.net/conteudo_detalhe.php?id=3039\&tipo=1\&criterio=Poder $>$. Acesso em 25 out. 2013.

. (Santa Catarina). Lei Municipal no 3.962 de 21 de março de 2000. Disponível em: $<$ http://camara.virtualiza.net/conteudo_detalhe.php?id=3854\&tipo=1\&criterio=Poder $>$. Acesso em 25 out. 2013.

GEHL, Jan; GEMZOE, Lars. Novos espaços urbanos. Barcelona, Espanha: Edição em português editorial Gustavo Gili, SA, 2002. 263p.

GOMES, Paulo Cesar da Costa. A condição urbana: ensaios de geopolítica da cidade. Rio de Janeiro: Bertrand Brasil, 2002. 304p.

GONÇALVES, Teresinha Maria; DESTRO, Diego; ROCHA, Maick. Ambiente urbano: as calçadas como espaços públicos na cidade de Criciúma, Santa Catarina, capital do carvão. In: MILIOLI, Geraldo. (Coord.); et al. Mineração de carvão, meio ambiente e desenvolvimento 
sustentável no sul de Santa Catarina: uma abordagem interdisciplinar. Curitiba, Pr.: Juruá Editora, 2009, p. 215 - 274.

INSTITUTO BRASILEIRO DE GEOGRAFIA E ESTATISTICA. CIDADES: Dados gerais do município de Criciúma - SC, 2013. Disponível em: $<$ http://cidades.ibge.gov.br/painel/painel.php?lang=\&codmun=420460\&search=santacatarina|criciuma|infograficos:-dados-gerais-do-municipio >. Acesso em 15 out. 2013.

IPAT - INSTITUTO DE PESQUISAS AMBIENTAIS E TECNOLÓGICAS. Elaboração dos insumos do plano diretor participativo do município de Criciúma (SC): mapa de bairros e localidades. 2007. Disponível em: <http://www.unesc.net/ pdp/pdf/PDP2007URB02-07103.pdf>. Acesso em 15 set. 2013.

JACOBS, Jane. Morte e vida de grandes cidades. Tradução Carlos S. M. Rosa. São Paulo: Martins Fontes, 2000. 510p.

LEFEBVRE, Henry. Direito à cidade. São Paulo: Editora Moraes, 1991.

POLICARPI, Claudeir. História do bairro Santa Luzia. Portal Rio Maina, Criciúma (SC), 2013. Disponível em: <http://www.portalriomaina.com.br/santa-luzia/historia〉. Acesso em 16 jun. 2013.

PREFEITURA de Santos (SP). Participação cidadã e gestão inovadora com o projeto Viva o Bairro. Santos (SP), 2013. Disponível em: <http://www.santos.sp.gov.br/aprefeitura/paginasinternas/88>. Acesso 16 out. 2013.

PREIS, Eduardo. As relações de poder no território e os planos diretores de Criciúma - SC. In: LADWIG, Nilzo Ivo; SCHWALM, Hugo. (orgs.). A gestão socioambiental das cidades no século XXI: Teorias, conflitos e desafios. Florianópolis: Insular, 2013, p. 79 - 103.

SANTOS, Milton. Por uma outra globalização: do pensamento único à consciência universal. Rio de Janeiro: Record, 2001. 174p.

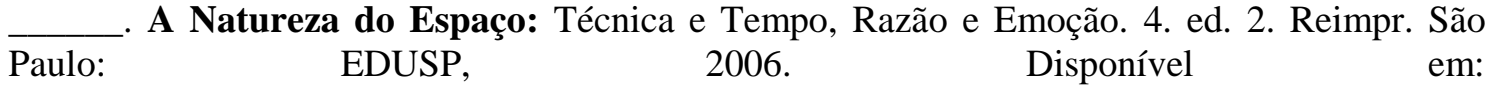
<http://www2.fct.unesp.br/docentes/geo/bernardo/TEORIA\%20DOS\%20TERRITORIOS\%20E $\% 20 D A \% 20 Q U E S T A O \% 20 A G R A R I A / M I L T O N \% 20 S A N T O S / S A N T O S$,_Milton_A_Naturez a_do_Espa\%C3\%A7o\%5B1\%5D.pdf>. Acesso 16 junho 2013.

SERPA, Ângelo. O espaço público na cidade contemporânea. São Paulo: Contexto, 2007. 205p.

SILVA, Aline Martins da. Atratividade e dinâmica de apropriação de espaços públicos para o lazer e turismo. 2009. 250f. Dissertação (Mestrado em Planejamento Urbano e Regional) Universidade Federal do Rio Grande do Sul, Porto Alegre. Disponível em: 〈http://www.ufrgs.br/propur/info/Aline_Silva.pdf $>$. Acesso em 05 jul. 2013.

SOUZA, Marcelo Lopes de. ABC do Desenvolvimento Urbano. 2. ed. Rio de Janeiro: Bertrand Brasil, 2005. 190p.

SOUZA, Marcelo Lopes de; RODRIGUES, Glauco Bruce. Planejamento urbano e ativismos sociais. São Paulo: Editora da UNESP, 2004. 133p.

SPÓSITO, Eliseu Savério. A vida nas cidades. 5. ed. São Paulo, Contexto, 2004. 90p.

VIEIRA, Ivanete de Mesquita Orsi. Configuração e Apropriação do Espaço Público: Estudo de duas Praças em Criciúma/SC. 2010. 109f. Dissertação (Mestrado em Urbanismo, História e Arquitetura da cidade) - Universidade Federal de Santa Catarina, Florianópolis. Disponível em: <http://antiga.pgau-cidade.ufsc.br/site/arquivos/1775_DEFESAFINAL.pdf〉. Acesso em 29 abril 2013. 